\title{
BANCR contributes to the growth and invasion of melanoma by functioning as a competing endogenous RNA to upregulate Notch2 expression by sponging miR-204
}

\author{
BINGJIE CAI $^{1}$, YUNPENG ZHENG ${ }^{1}$, SHANSHAN MA ${ }^{2}$, QU XING $^{2}$, XINXIN WANG $^{1}$, \\ BO YANG ${ }^{1}$, GUANGWEN YIN ${ }^{1}$ and FANGXIA GUAN ${ }^{1,2}$ \\ ${ }^{1}$ The First Affiliated Hospital of Zhengzhou University, Zhengzhou, Henan 450052; \\ ${ }^{2}$ School of Life Sciences, Zhengzhou University, Zhengzhou, Henan 450001, P.R. China
}

Received May 8, 2017; Accepted September 27, 2017

DOI: $10.3892 /$ ijo.2017.4173

\begin{abstract}
BRAF-activated non-coding RNA (BANCR) is a long non-coding RNA (lncRNA) that contributes to the initiation and development of many solid tumors, including melanoma. However, the BANCR functions and downstream mechanisms are largely unknown. In this study, we aim to investigate how BANCR participates in the proliferation and migration of malignant melanoma and elucidate the underlying mechanism in this process. We found that the expression of the BANCR was low in melanocytic nevus and human melanocytes but high in melanoma tissues and cell lines. Knockdown of BANCR inhibited melanoma cell proliferation and invasion, and induced cell apoptosis. The decreased expression of relative marker proteins further demonstrated the inhibitory effect of BANCR siRNA in cell growth and migration. Then, we detected downregulation of microRNA-204 (miR-204), a suppressor of melanoma growth, in melanoma tissues and cell lines. We identified that miR-204 was a direct target of BANCR and neurogenic locus notch homolog protein 2 (Notch2) was a direct target of miR-204. BANCR may promote melanoma cell growth through inhibition of miR-204, leading to the activation of Notch2 pathway. By tumorigenicity assay in $\mathrm{BALB} / \mathrm{c}$ nude mice, we further demonstrated that BANCR knockdown inhibited tumor growth in vivo. Our results suggest the BANCR/miR-204/Notch2 axis mediates melanoma cell proliferation and tumor progression.
\end{abstract}

Correspondence to: Professor Fangxia Guan or Dr Guangwen Yin, The First Affiliated Hospital of Zhengzhou University, 1 East Jianshe Road, Zhengzhou, Henan 450052, P.R. China

E-mail: gfangx2017@163.com

E-mail: xguangwenyiny@outlook.com

Abbreviations: BANCR, BRAF-activated non-coding RNA; lncRNAs, long non-coding RNAs; miR, microRNA; Notch2, neurogenic locus notch homolog protein 2

Key words: lncRNA, BANCR, miR-204, Notch2, melanoma

\section{Introduction}

Melanoma, a malignant tumor of melanocytes, is one of the most frequent malignancies and considered to be the most aggressive type of skin cancer $(1,2)$. Melanoma is characterized by rapid progression and poor prognosis, mainly due to the limited efficiency of treatments and development of resistance to chemotherapy $(3,4)$. Although melanoma accounts for $<1 \%$ of skin cancer cases, it contributes to the majority of deaths that result from skin cancer. It is estimated that one person will die from melanoma every hour (5). Despite of the recent advances in anti-melanoma chemotherapies and immunotherapies, currently available treatment strategies are only able to prolong life for just a few months before the disease relapses, leading to death $(6,7)$. Therefore, there is an urgent need for novel therapeutic strategies to improve clinical outcomes for these patients.

Long non-coding RNAs (lncRNAs), ranging from 200 nucleotides to over $10 \mathrm{~kb}$, have been found to dysregulate in many human diseases and disorders, including various types of cancer $(8,9)$. lncRNAs have demonstrated potential roles in both oncogenic and tumor suppressive pathways (10). For example, both MEG3 and GAS5 exert oncogenic activities in gastric cancer, and the overexpression of them is often associated with poor prognosis $(11,12)$. MALAT1 promotes osteosarcoma growth, also exerting an oncogenic activity (13). BRAF-activated non-coding RNA (BANCR), a 693-bp lncRNA on chromosome 9, has been reported to exert oncogenic acvities in many cancers under some specific conditions, such as non-small cell lung cancer, papillary thyroid carcinoma and colorectal cancer (14-16). Recent studies reported that BANCR is abnormally overexpressed in human malignant melanoma cell lines and tissues, and promotes proliferation and migration in malignant melanoma $(17,18)$. These results suggest the oncogenic role and potential of BANCR as a therapeutic target for melanoma. While these findings demonstrate a clear correlation between BANCR and melanoma, the specific effect of BANCR on melanoma tumorigenesis and the mechanisms involved remain to be investigated.

MicroRNAs (miRNAs, miRs), about 22 nucleotides long, regulate the expression of most genes in human, but we are 
only now beginning to understand how they are generated, assembled into functional complexes and degraded (19). Recent studies reported that the interplay between miRNAs and lncRNAs plays an important role during the tumorigenic process, providing new insight into the possible regulatory mechanisms in cancers. For example, BANCR promotes endometrial cancer cell proliferation and invasion by regulating MMP2 and MMP1 via ERK/MAPK signaling pathway (20). Particularly, many $\operatorname{lncRNA} / \mathrm{miRNA}$ axes were reported to function in melanoma. IncRNA CCAT1 upregulates proliferation and invasion in melanoma cells via suppressing miR-33a (21). Besides, deregulation of miR-183 promotes melanoma development via lncRNA MALAT1 regulation (22). These studies illustrate that the IncRNAmiRNA interaction might be important in the process of melanoma, laying the foundation for current study. The Notch signaling through Notch receptors regulates cell proliferation and cell survival in several types of cancer including melanoma. A previous study showed that the activation of Notch may represent an early event in melanocytic tumor growth and upregulation of this pathway may sustain tumor progression (23). Also, other studies showed that the activation of Notch pathway can be controlled by microRNAs in melanoma. For example, miR-146a promotes the initiation and progression of melanoma by activating Notch signaling (24). In this study, we aimed to investigate the effects of BANCR/miR-204/Notch2 axis on the regulation of melanoma and the possible mechanisms underlying these actions, and to provide a new aspect for development of novel treatment strategies.

\section{Materials and methods}

Cell culture and tissues. Three human melanoma cells lines, including A375, A875 and M14, and human epidermal melanocytes were obtained from Regenerative Medicine Research Center/Key Laboratory of Transplant Engineering and Immunology, Ministry of Health, West China Hospital, Sichuan University. Cells were maintained in DMEM (Gibco, Rockville, MD, USA) supplemented with $10 \%$ fetal bovine serum (FBS, Gibco), $100 \mathrm{U} / \mathrm{ml}$ penicillin and $100 \mathrm{mg} / \mathrm{ml}$ streptomycin (Gibco). Human epidermal melanocyte was cultured in medium 245 contained melanocyte growth supplement (Cascade Biologics, USA). All cell lines were incubated at $37^{\circ} \mathrm{C}$ in $5 \% \mathrm{CO}_{2}$ incubator. Fresh melanoma tissue samples and age/gender-matched controls with melanocytic nevus were obtained from 69 patients with advanced melanoma who underwent surgery in the First Affiliated Hospital of Zhengzhou University. All collected tissue samples were immediately frozen in liquid nitrogen and stored at $-80^{\circ} \mathrm{C}$ until further use. The study was approved by the institutional review board of the hospital, and written informed consent was obtained from each patient. All diagnoses were confirmed by histopathological examination.

Lentivirus transduction. According to the pre-experiment, the expression level of BANCR was overexpressed in A375, A875 and M14 cells compared with melanocytes. We chose A375 and M14 for further investigations, for the expression of BANCR was higher in A375 and M14 compared with cell lines A875. Recombinant lentiviruses containing BANCR
shRNAand shRNA scramble were purchased from Shanghai GenePharma Co, Ltd (Shanghai, China). The sequences of these shRNAs are: sh-BANCR-1: forward, 5'-GGACUCCAUG GCAAACGUUTT-3' and reverse, 5'-AACGUUGCCAUGGA GUCCTT-3'; sh-BANCR-2, forward, 5'-GGAGUGGCGACU AUAGCAATT-3' and reverse, 5'-UUGCUAUAGUCGCCAC UCCTT-3'; shRNA scramble: forward, 5'-UUCUCCGAACG UGUCACGUTT-3' and reverse, 5'-ACGUGACACGUUCGGA GAATTT-3'. According to the pre-experiment, decreased level of BANCR was detected under sh-BANCR-1 treatment, but a slight change was measured after sh-BANCR-2 transfection. Thus, sh-BANCR-1 (BANCR shRNA) was chosen for further study. The BANCR shRNAand shRNA scramble were transfected into A375 and M14 cells cultured in six-well plates by using Lipofectamine 2000 (Invitrogen, Carlsbad, CA, USA), according to the manufacturer's instructions. The MOI of these recombinant lentiviruses in cells were at 20. Mimics/ inhibitors specific for miR-204 were designed and purchased from Shanghai GenePharma Co, Ltd (Shanghai, China). Lentivirus transduction was performed on the tenth day of A375 and M14 cells culture. One day before transduction, both cells were seeded at a density of $1 \times 10^{5}$ cells/well into a 24-well culture plate. Cells were harvested for subsequent experiments after transfection for $48 \mathrm{~h}$. All above vectors were transfected into cells with Lipofectamine 2000 (Invitrogen) according to the manufacturer's instructions.

RNA extraction and real-time PCR. RNA extraction of the cells or tissue samples was performed using TRIzol reagent (Invitrogen) according to the manufacturer's instructions. A High Capacity cDNA Reverse Transcription kit (Applied Biosystems, USA) was used to reverse transcribe RNA samples. The primers used were as follows: GAPDH: forward, 5'-AATCCCATCACCATCTTCCAG-3' and reverse, 5'-GAGCCCCAGCCTTCTCCAT-3'; BANCR, forward, 5'-ACAGGACTCCATGGCAAACG-3' and reverse, 5'-ATGA AGAAAGCCTGGTGCAGT-3'; miR-204, forward, 5'-CTGTC ACTCGAGCTGCTGGAATG-3' and reverse, 5'-ACCGTGTC GTGGAGTCGGCAATT-3'. To analyze the gene expression, quantitative RT-PCR was performed using the Fast Start Universal SYBR Green Mastermix (Roche, USA). GAPDH was used as the internal control. Relative gene expression was analyzed by $2^{-\Delta \Delta \mathrm{Ct}}$ method.

Cell counting kit-8 assay. Cell Proliferation assay using the cell counting kit-8 (CCK-8; Dojindo, Japan) was performed according to the manufacturer's instructions. Briefly, cells were seeded into 96 -well plates at a density of $5 \times 10^{3}$ cells per well with complete growth medium. After 24-h incubation, the cells were transfected with BANCR shRNAor shRNA scramble. After 48-h of culture, the growth medium was removed from each well, and then all the wells were filled with $100 \mathrm{ml}$ of fresh medium containing $10 \mathrm{ml}$ CCK-8 solutions. After incubated for $2 \mathrm{~h}$ at $37^{\circ} \mathrm{C}$, cell proliferation was assessed by absorbance detection at $450 \mathrm{~nm}$ with a microplate reader (Biotek, Winooski, VT, USA).

Western blotting. RIPA buffer (Sigma-Aldrich, St. Louis, MO, USA) was used to lyse cells with Complete Protease Inhibitor Cocktail (Roche). Cell lysates at a density of 7x10 6 cells 
were transferred to $1.5 \mathrm{ml}$ tube and kept at $-20^{\circ} \mathrm{C}$ before use. The protein concentration was determined by BCA protein assay (Tiangen, China). Twenty micrograms of protein in each sample was separated by $12 \%$ SDS-PAGE, which was conducted to separate the cellular proteins. Proteins were separated by $5 \%$ stacking gel and $10 \%$ running gel. After blocking for $1 \mathrm{~h}$, the membranes were incubated with specific primary antibodies overnight at $4^{\circ} \mathrm{C}$ followed by secondary antibodies for $2 \mathrm{~h}$ at room temperature. The molecular weight of candidate proteins was referred to the Pre-stained SeeBlue rainbow marker (Invitrogen) loaded in parallel. The following antibodies were used: anti-Ki-67, anti-PCNA, anti-caspase-3, anti-Bcl-2, anti-MMP-9 (active), anti-MMP-14, anti-VEGF, anti-Notch2, anti-NICD, anti-CSL (Abcam, Cambridge, UK), anti-GAPDH (Sigma, St. Louis, MO, USA). Blots were detected using a Kodak film developer (Fujifilm, Japan).

Cell apoptosis analysis. Cell apoptosis was analyzed after appropriate plasmids transfection using staining with Annexin V and PI (BD Bioscience, San Jose, CA) according to the manufacturer's instructions. After incubated for $15 \mathrm{~min}$ at room temperature in the dark, the cells were analyzed by using a flow cytometry. Annexin V-positive and PI-negative/positive staining cells represent apoptotic cells.

Transwell migration assay. After transfection for $48 \mathrm{~h}$, the cells were seeded onto the upper part of a Transwell chamber (Corning Costar, Rochester, NY, USA) containing a gelatincoated polycarbonate membrane filter (pore size, $8 \mu \mathrm{m}$ ). Culture medium with $20 \%$ FBS was added to the lower chamber to stimulate cell migration. After 24-h incubation at $37^{\circ} \mathrm{C}$ with $5 \% \mathrm{CO}_{2}$, the cells were stained with crystal violet (Sigma-Aldrich, Germany). Cells on the underside of the filters were observed under a microscope (Olympus IX71; Olympus Corp., Tokyo, Japan) at a magnification of x100 and counted.

Wound healing assay. After transfection for $48 \mathrm{~h}$, the subconfluent cell monolayers were scraped in three parallel lines with a P-200 pipette tip. The detached cells were washed off twice gently, and the medium was then replaced with $1 \%$ FBS complete medium. To visualize wound healing, images were taken at 0 and $24 \mathrm{~h}$. The percentage of wound closure (original width-width after cell migration/original width) was calculated.

Zymography. The activities of MMP-2 and MMP-9 were measured by gelatin zymography according to a previous report (25). Briefly, proteins were separated by electrophoresis on a $10 \%$ polyacrylamide gel (Sigma-Aldrich, USA). Gels were washed for $1 \mathrm{~h}$ and incubated in $50 \mathrm{mM}$ Tris- $\mathrm{HCl}$ buffer, pH 7.2, containing $10 \mathrm{mM} \mathrm{CaCl}_{2}, 0.02 \% \mathrm{NaN}_{3}$, and $2.5 \%$ Triton $\mathrm{X}-100$ for $20 \mathrm{~h}$ at $37^{\circ} \mathrm{C}$. Gels were stained with $0.1 \%$ Coomassie Blue R-250 in 20\% methanol, and $10 \%$ acetic acid, and de-stained in $20 \%$ methanol and $10 \%$ acetic acid. MMP-2 and MMP-9 activities were detected as clear bands on a blue background. Zymograms were captured by gel visualization system and quantified with gene tools software (Syngene, Cambridge, UK). The activities of gelatinases were expressed as the optical density of the substrate lysis zone.
Luciferase reporter assay. The Luc-BANCR-WT and Luc-BANCR-MUT were constructed as follows. The wild-type BANCR and mutant BANCR were amplified by chemical synthesis and were inserted into a luciferase reporter vector (pGL4.74) to generate Luc-BANCR-WT and Luc-BANCR-MUT constructs, respectively. M14 cells cultured in 24-well plates were co-transfected with Luc-BANCR-WT/Luc-BANCR-MUT, together with miR-204 mock or miR-204 mimic for $24 \mathrm{~h}$. Luciferase activities were detected by a dual-luciferase reporter system according to the manufacturer (E2920; Promega). The data are measured using the ELISA plate reader (Bio-Rad, USA) at the wavelength of $490 \mathrm{~nm}$.

Bioinformatic study. In silico prediction of the interaction between BANCR/miR-204 or miR-204/Notch2, were performed using Diana Tools. In addition, Mut-BANCR transcript was prepared according to the binding sites of miR-204 within BANCR transcript.

Animal study. Male BALB/c mice (18-20 g, 4-5 weeks old) were purchased from Beijing HFK Bioscience Co. Ltd. and kept under sterile specific pathogen-free conditions. All experiments were approved by the Animal Care and Ethics Committee of the First Affiliated Hospital of Zhengzhou University and were in accordance with NIH animal use guidelines. M14 cells were transfected with BANCR shRNA or shRNA scramble and harvested from 6-well cell culture plates. Approximately $2 \times 10^{6}$ cells in $50 \%$ Matrigel (Becton-Dickinson, San Diego, CA, USA) were injected subcutaneously into the right flanks of the mice. Tumor growth was measured every 5 days, and tumor volume was calculated using the formula, volume = $1 / 2$ (length $x$ width ${ }^{2}$ ). Twenty-five days after injection, the mice were sacrificed and tumor weights were measured.

Statistical analysis. Experimental values were obtained from at least three independent experiments. Data are expressed as means \pm SD. Statistical analysis was performed by using the Student's t-test or one-way analysis of variance (GraphPad Prism; GraphPad Software Inc, La Jolla, CA, USA), where appropriate. The Bonferroni post hoc test was used to determine the source of observed differences. P-values of $<0.05$ were considered statistically significant.

\section{Results}

BANCR is frequently upregulated in malignant melanoma tissues and cell lines. The expression of BANCR in melanoma tissues and cell lines was evaluated using SYBR green quantitative PCR analysis by real-time PCR. As shown in Fig. 1A, a significantly increased level of BANCR was seen in patients with malignant melanoma compared with the levels detected in age/gender-matched controls with melanocytic nevus $(\mathrm{P}<0.01)$. Then we extended our test to three human melanoma cell lines (A375, A875 and M14). As expected, high-level expression of BANCR was observed in all three melanoma cell lines compared with human epidermal melanocytes $(\mathrm{P}<0.01$, Fig. $1 \mathrm{~B})$. These results suggest that BANCR may play an important role in the development and progression of melanoma. 

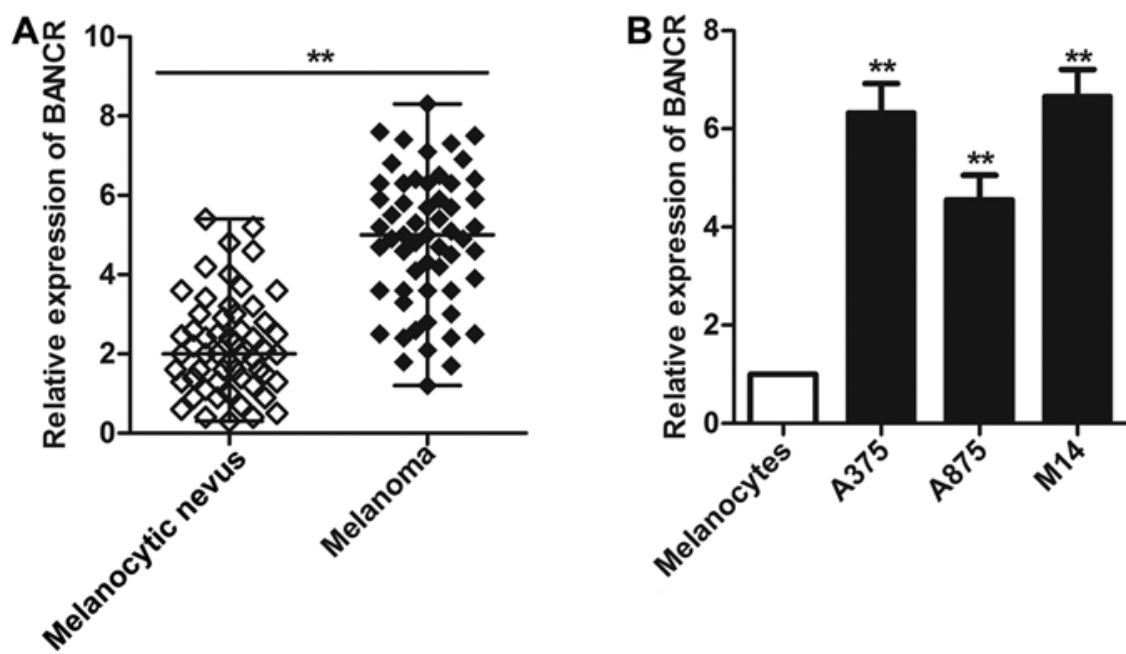

Figure 1. Expression of BANCR was detected in malignant melanoma tissues and cell lines. (A) BANCR expression in malignant melanoma tissues and melanocytic nevus. (B) BANCR expression in three melanoma cell lines (A375, A875 and M14) and human epidermal melanocytes. Data are presented as means \pm SD of three independent experiments. ${ }^{* *} \mathrm{P}<0.01$ compared with the control group.

Knockdown of BANCR inhibits melanoma cell proliferation in vitro. According to previous results, the overexpression of BANCR was observed in all three cell lines. The expression level of BANCR in A875 is a little lower compared with cell lines A375 and M14, so we chose A375 and M14 for further investigation. To determine the association of BANCR expression with melanoma cell proliferation and apoptosis, BANCR shRNA or LV-NC (negative control) were transfected into two human melanoma cell lines: A375 and M14. Compared with the control group, BANCR expression was decreased in cells transfected with BANCR shRNA as measured by realtime $\mathrm{qPCR}(\mathrm{P}<0.01$, Fig. $2 \mathrm{~A})$. Then, the effects of BANCR knockdown on the growth of melanoma cells in vitro was measured by CCK- 8 assays. When compared with the control group, BANCR knockdown restrained the proliferation folds of both A375 and M14 cell lines (P<0.05, Fig. 2B). To better understand the influence of BANCR on the melanoma cell proliferation, the expression of Ki-67 and PCNA in the melanoma cell lines A375 and M14 was assayed by western blotting $(\mathrm{P}<0.01$ and $\mathrm{P}<0.05$, respectively, Fig. $2 \mathrm{C})$. The expression level of Ki-67 and PCNA were significantly reduced after transfection with BANCR shRNA compared with control group. These data strongly support a requirement for BANCR in the proliferation of melanoma cells. Moreover, to explore potential mechanisms underlying the growth-inhibitory effects of BANCR knockdown, we assessed cell apoptosis in A375 and M14 cells by flow cytometry analysis. As shown in Fig. 2D, the proportion of apoptotic cells in the BANCR shRNA group was significantly increased in comparison with that in the control group. To further understand the influence of BANCR on the melanoma cell apoptosis, the expression of cleaved caspase- 3 and Bcl-2 in the melanoma cell lines A375 and M14 were assayed by western blotting ( $\mathrm{P}<0.01$, Fig. 2E). The expression cleaved caspase-3 in BANCR shRNA group obviously increased compared with the control group, while the expression of Blc-2 reduced.

Knockdown of BANCR suppresses melanoma cell migration and invasion in vitro. The effect of BANCR on the migratory capability was assessed by Transwell chamber assay and wound healing assay in A375 and M14 cells. As illustrated in Fig. 3A, the Transwell assay showed that the number of migratory cells in the BANCR shRNA group was significantly decreased compared with that in the control group $(\mathrm{P}<0.001)$. The wound healing assay also exhibited that the closing rate of scratch wounds was significantly decreased by BANCR knockdown compared with the control group ( $\mathrm{P}<0.001$, Fig. 3B). To better understand the influence of BANCR on the melanoma cell migration and invasion, the expression of MMP-9, MMP-14 and VEGF in the melanoma cell lines A375 and M14 were assayed by western blotting $(\mathrm{P}<0.01$, Fig. $2 \mathrm{C})$. In addition, the activity of MMP2 and MMP-9 was significantly decreased under BANCR shRNA treatment by zymography assay $(\mathrm{P}<0.01$, Fig. 3D). These results imply that BANCR is involved in the promotion of melanoma cell motility.

miR-204 is a direct target of BANCR. Growing evidence supports that miR-204 may functions as a tumor suppressor and plays a prominent role in the development of several cancers under some specific conditions (26-28). Bioinformatics analyses predicted that BANCR might be a putative target gene of miR-204, suggesting a potential interaction between miR-204 and BANCR (Fig. 4A). Then, we examined expression level of miR-204 in melanoma tissue samples and melanoma cell lines (A375, A875 and M14). As illustrated in Fig. 4B and C, miR-204 was significantly downregulated in melanoma tissues compared with the melanocytic nevus $(\mathrm{P}<0.01)$, while low-level expression of miR-204 was also observed in melanoma cell lines rather than the human epidermal melanocytes $(\mathrm{P}<0.01)$.

Considering the expression of miR-204 was lower in A375 and M14 cells compared with cell lines A875. A375 and M14 were chosen for the following experiments. To investigate whether miR-204 is a direct target of BANCR, A375 and M14 cells were transfected with BANCR shRNA or shRNA scramble. The results showed that BANCR knockdown significantly caused upregulation of miR-204 compared with control group $(\mathrm{P}<0.001$, Fig. 4D). Then, we generated two luciferase reporter constructs: a wt-BANCR and a mut-BANCR. The 
A

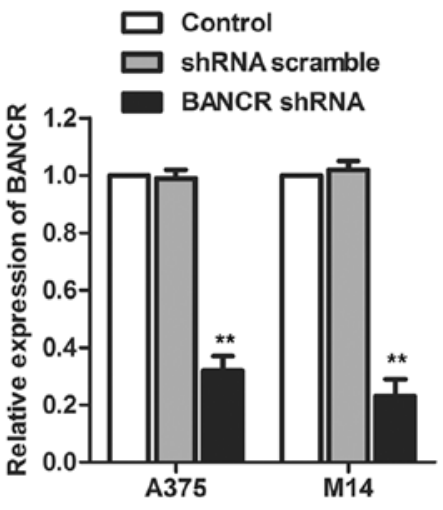

C

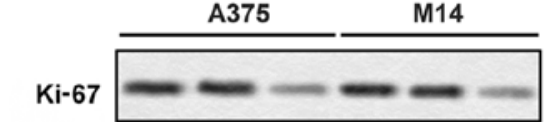

PCNA

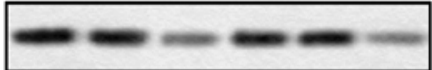

GAPDH
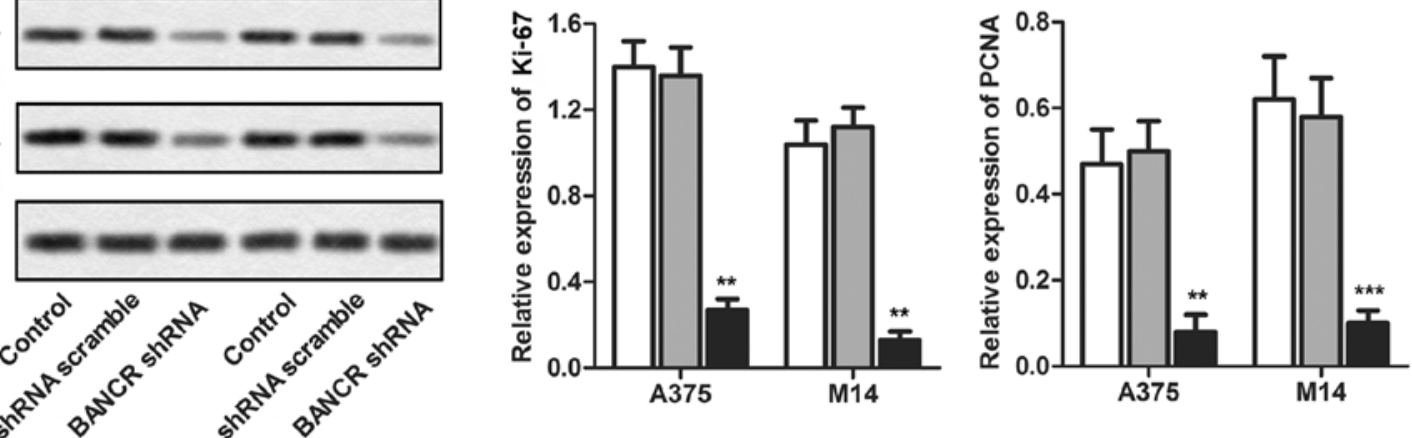
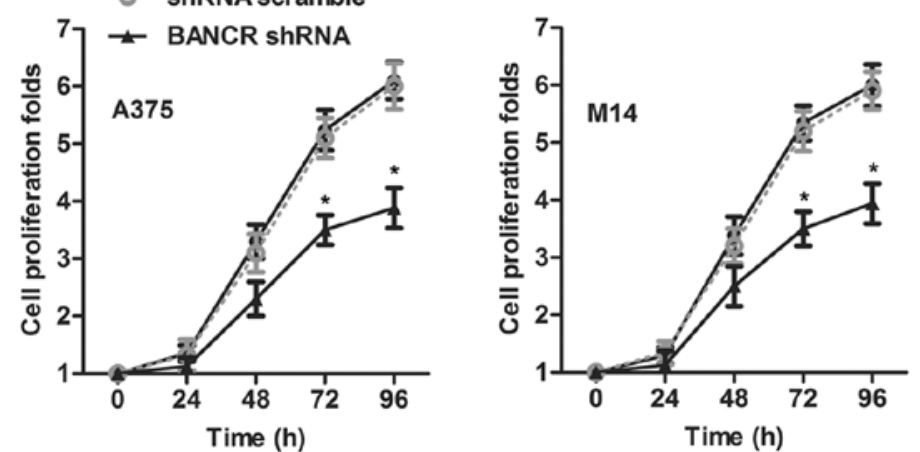

B $\quad \rightarrow$ Control

D

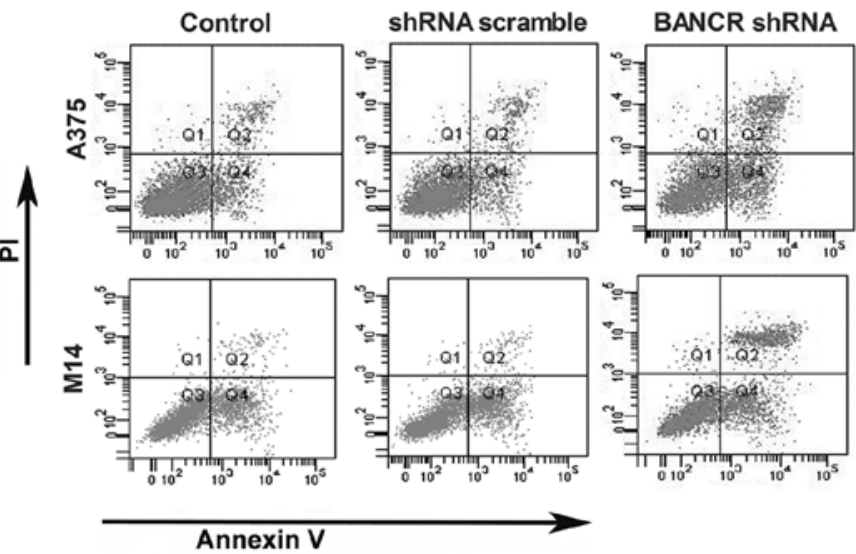

E

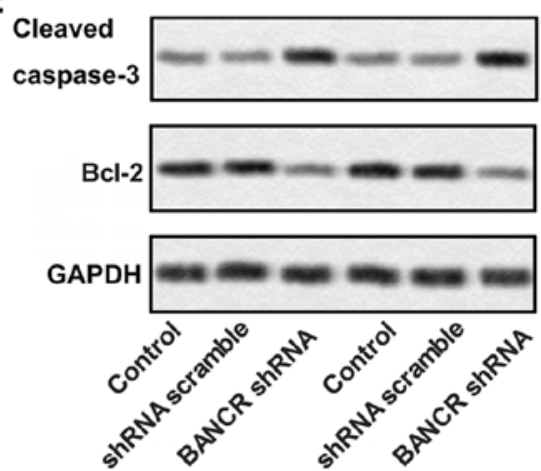

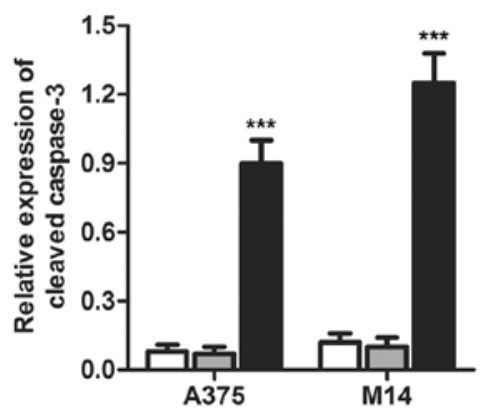

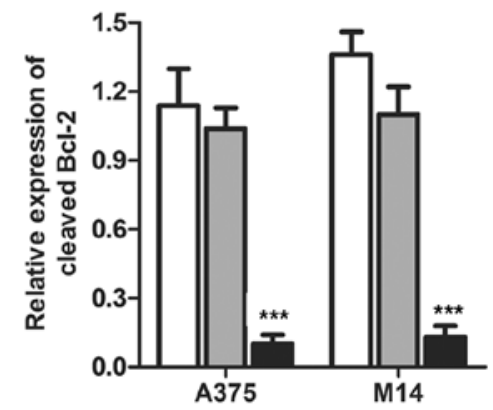

Figure 2. Effects of BANCR on melanoma cell proliferation. Both A375 and M14 cells were transfected with BANCR shRNA or shRNA scramble. (A) BANCR knockdown was achieved by BANCR shRNA and the inhibitory efficiency was verified by real-time qPCR. (B) The proliferation of melanoma cells was determined by CCK-8 assay. (C) Expression of Ki-67 and PCNA was detected in two melanoma cell lines by western blot analysis. GAPDH was used as a loading control. (D) Flow cytometric analysis of apoptotic cells by Annexin V and PI double staining. (E) Expression of caspase-3 and Bcl-2 was measured in melanoma cells. Data are presented as means \pm SD of three independent experiments. $\mathrm{P}<0.05,{ }^{* *} \mathrm{P}<0.01$ and ${ }^{* * * *} \mathrm{P}<0.001$ compared with the control group. 
A
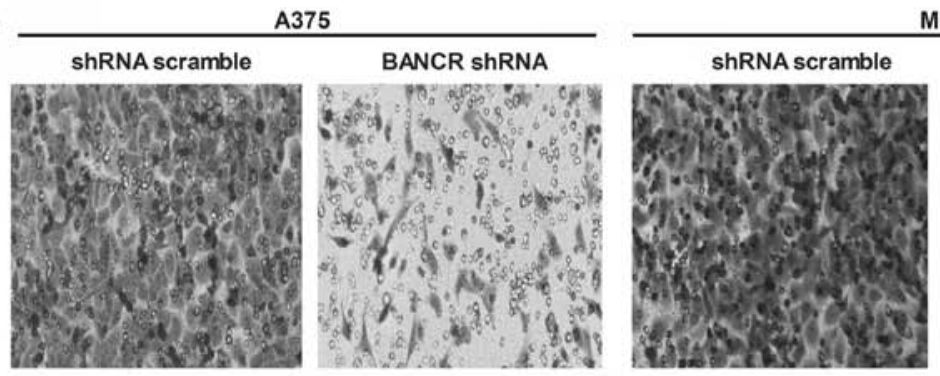
M14
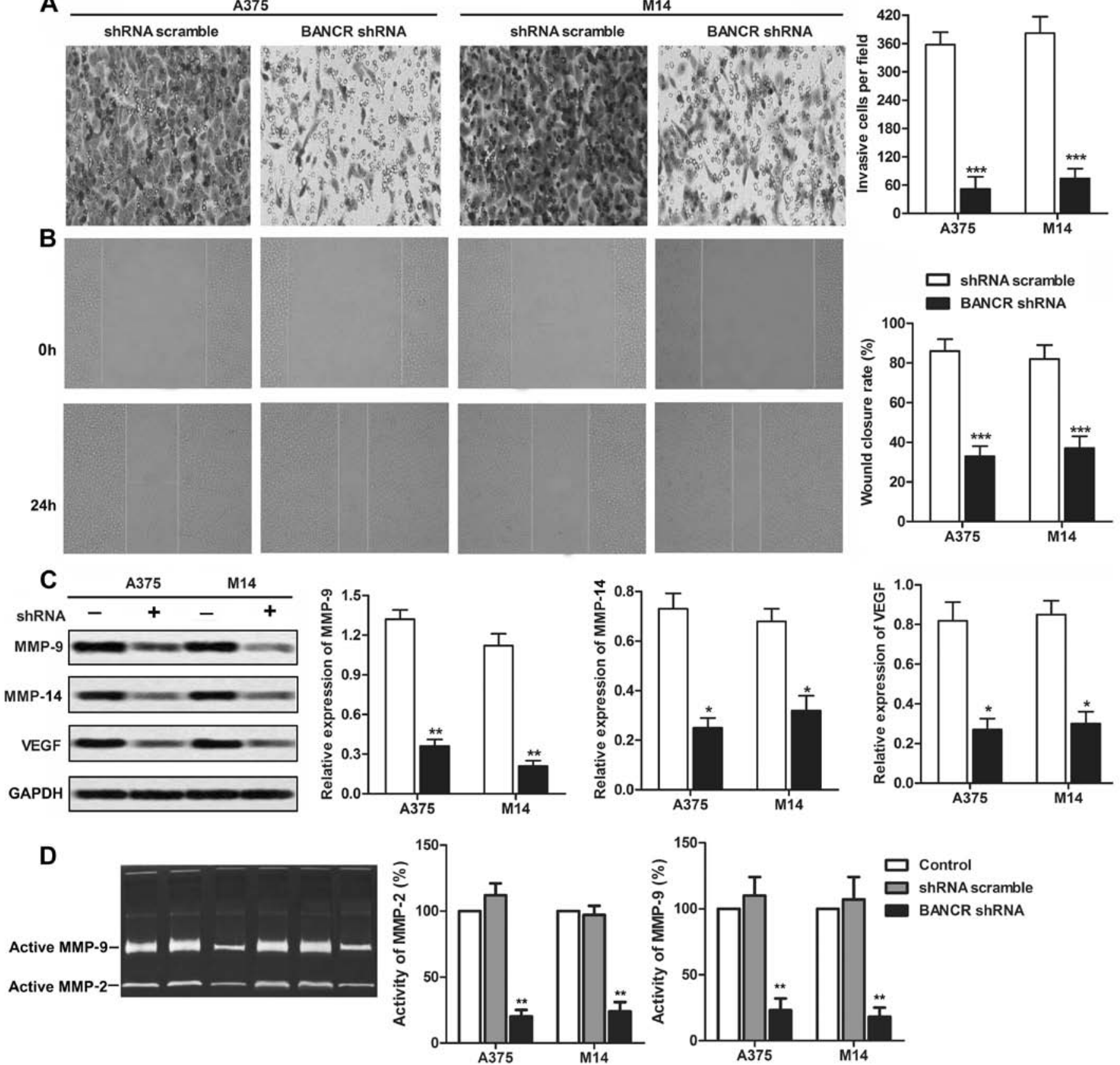

Figure 3. Effects of BANCR on melanoma cell migration and invasion. Both A375 and M14 cells were transfected with BANCR shRNA or shRNA scramble. (A) Representative micrographs (left) and quantification (right) of the Transwell migration assay in the A375 and M14 cells. (B) Representative micrographs (left) and quantification (right) of the wound healing assay for A375 and M14 cells. (C) Expression of MMP-9, MMP-14 and VEGF was measured in both A375 and M14 cells by western blot analysis. (D) MMP-2 and MMP-9 activities were determined by gelatin zymography. Data are expressed as means \pm SD of three independent experiments. ${ }^{*} \mathrm{P}<0.05,{ }^{* * *} \mathrm{P}<0.01$ and ${ }^{* * * *} \mathrm{P}<0.001$ compared with the control group.

mut-BANCR contained a 3 bp mutation in the putative miR-204 binding site (Fig. 4A). We use wt BANCR transfected cells for convincing the targeting relationship between BANCR and miR-204. The wild-type BANCR and mutant BANCR were inserted into a luciferase reporter vector (pGL4.74) for luciferase reporter assay. Considering the high levels of BANCR, these wt-BANCR and mut-BANCR vectors and miR-204 scramble or miR-204 mimic were co-transfected into M14 cells, respectively. When compared with the control group, luciferase activity of the wt-BANCR vector deceased in cells transfected with miR-204 mimic $(P<0.05$, Fig. 4E). The repression of luciferase activity by miR-204 was not seen in cells transfected with mut-BANCR (Fig. 4E). These results suggested a direct interaction between miR-204 and BANCR via the 3-bp putative miR-204 binding site.

miR-204 is involved in the growth and migration of melanoma. We further investigated the role of miR-204 in melanoma, CCK8 assay displayed that the restrained proliferation of M14 cells was enhanced adding miR-204 inhibitor in BANCR shRNA group $(\mathrm{P}<0.05$, Fig. 5A). Moreover, we assessed cell apoptosis in M14 cells by flow cytometry analysis. As shown in Fig. 5B, the proportion of apoptotic cells in the miR-204 inhibitor group co-transfected with BANCR shRNA was 


\section{A BANCR MUT \\ BANCR WT chr9:70809975-10084 (-)}

hsa-miR-204

$B$

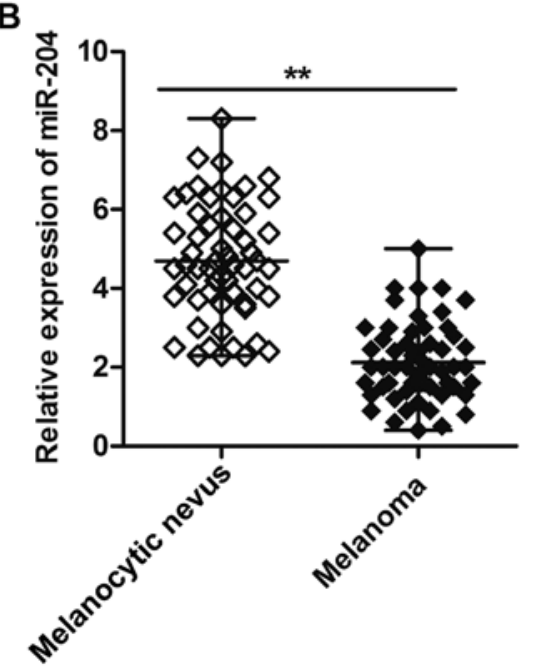

D

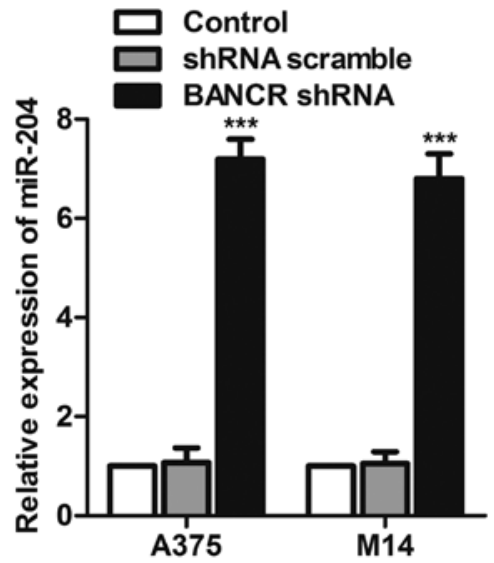

...UGGAC U UCCCUUUGUC A UCGGU GCCU. ...UGGAC U UCCCUUUGUC A UCCUA GCCU.

$$
\text { I| |||||||||| ||||||| }
$$$$
\text { UG CAGGGAAACGG A AGGGUCG }
$$

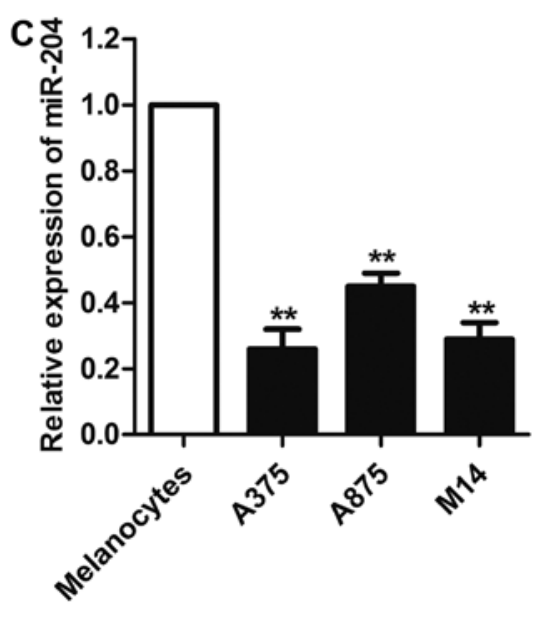

$\mathbf{E}$

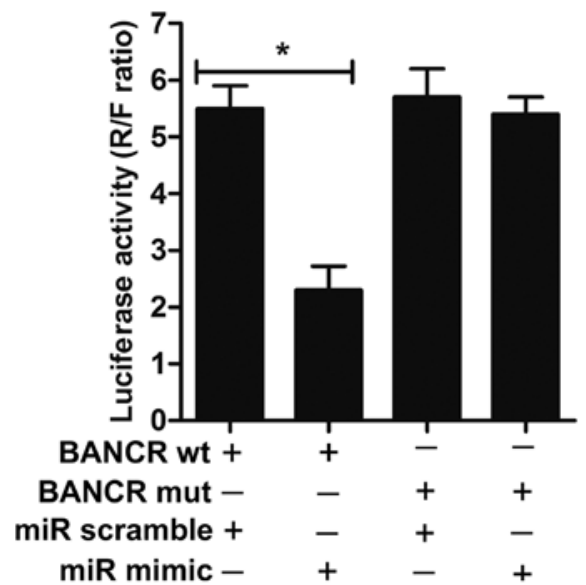

Figure 4. Direct interaction between miR-204 and BANCR in vitro. (A) A schematic of the bioinformatics predicted seed region in BANCR is shown above. The mutated BANCR used in this study is also shown. (B) Expression of miR-204 in malignant melanoma tissues and melanocytic nevus was detected by real-time qPCR. ${ }^{* *} \mathrm{P}<0.01$ compared with the melanocytic nevus group. (C) Expression of miR-204 in three melanoma cell lines (A375, A875 and M14) and human epidermal melanocytes. ${ }^{* *} \mathrm{P}<0.01$ compared with the human epidermal melanocytes. (D) Expression of miR-204 was measured in A375 and M14 cells transfected with BANCR shRNA or shRNA scramble by real-time qPCR assay. ${ }^{* * *} \mathrm{P}<0.001$ compared with the control group. (E) The wt-BANCR/mut-BANCR vectors and miR-204 mock/mimic were co-transfected into M14 cells, respectively. Luciferase activity of the wt-BANCR/mut-BANCR vectors were detected. ${ }^{*} \mathrm{P}<0.05$ compared with the miR scramble group. Data are presented as mean $\pm \mathrm{SD}$ of three independent experiments.

significantly lower than that in BANCR shRNA group $(\mathrm{P}<0.001)$. In addition, to assess the effect of miR-204 on the melanoma cell migratory capability, wound healing assay and Transwell chamber assay were performed in M14 cells. As illustrated in Fig. 5C, the wound healing assay showed that miR-204 inhibitor group co-transfected with BANCR shRNA promoted the ability of melanoma cells to close a gap compared with BANCR shRNA group $(\mathrm{P}<0.05)$. Also, for the migratory cells in the miR-204 inhibitor group co-transfected with BANCR shRNA was obviously increased compared with that in BANCR shRNA detected by the Transwell assay $(\mathrm{P}<0.01$, Fig. 5D). Together, these data demonstrated that
miR-204 inhibited melanoma cell proliferation and migration.

BANCR knockdown restrains the activation of Notch 2 pathway. Bioinformatics analyses predicted that miR-204 might be a putative target gene of Notch2 (Fig. 6A). To convince their target relationship, we measured the expression of Notch2, NICD and CSL in response to BANCR shRNA or shRNA scramble co-transfected with miR-204 scramble or miR-204 inhibitor in human melanoma cell line M14. The expression level of Notch2, NICD and CSL were downregulated by knockdown of BANCR compared with shRNA 
A

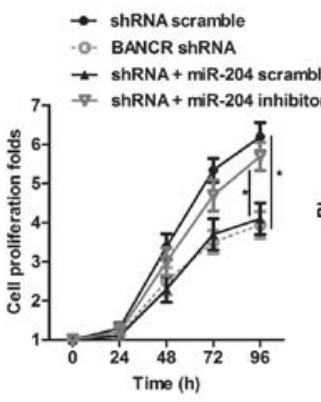

C
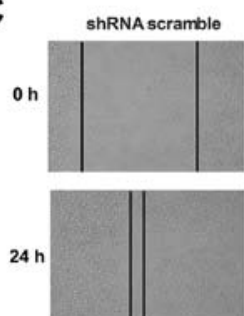

D

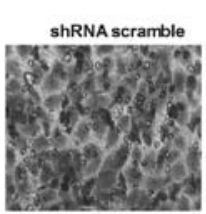

BANCR ShRNA
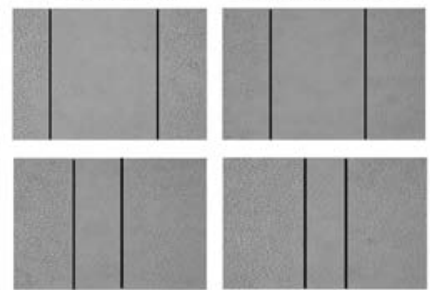

BANCR ShRNA

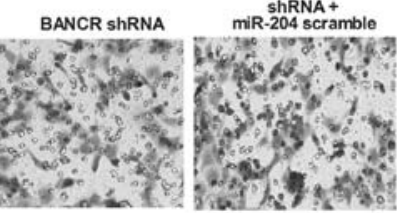

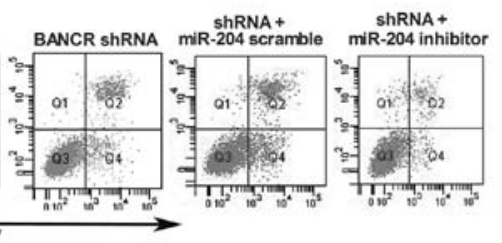

B

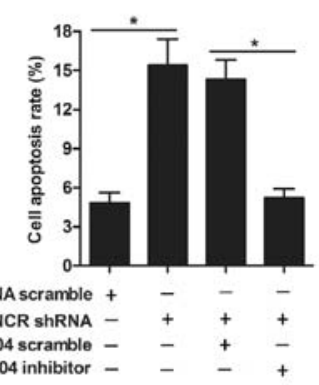

Figure 5. Effects of miR-204 on melanoma cell growth, apoptosis and migration. M14 cells were transfected with BANCR shRNA or shRNA scramble in combination with miR-204 mock or miR-204 inhibitor. (A) The proliferation of M14 cells transfected with grouped plasmids was determined by CCK-8 assay. (B) Flow cytometric analysis of apoptotic cells (M14) transfected with grouped plasmids by Annexin V and PI double staining. (C) Wound healing assay for M14 cells transfected with grouped plasmids. (D) Representative micrographs (left) and quantification (right) of the Transwell migration assay in the M14 cells. Data are presented as mean $\pm \mathrm{SD}$ of three independent experiments. ${ }^{*} \mathrm{P}<0.05$ and ${ }^{* *} \mathrm{P}<0.01$ indicates significant difference.

A

hsa-miR-204 3

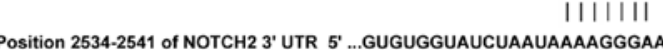
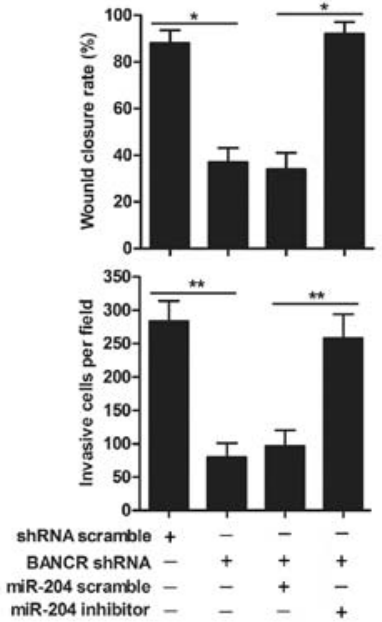

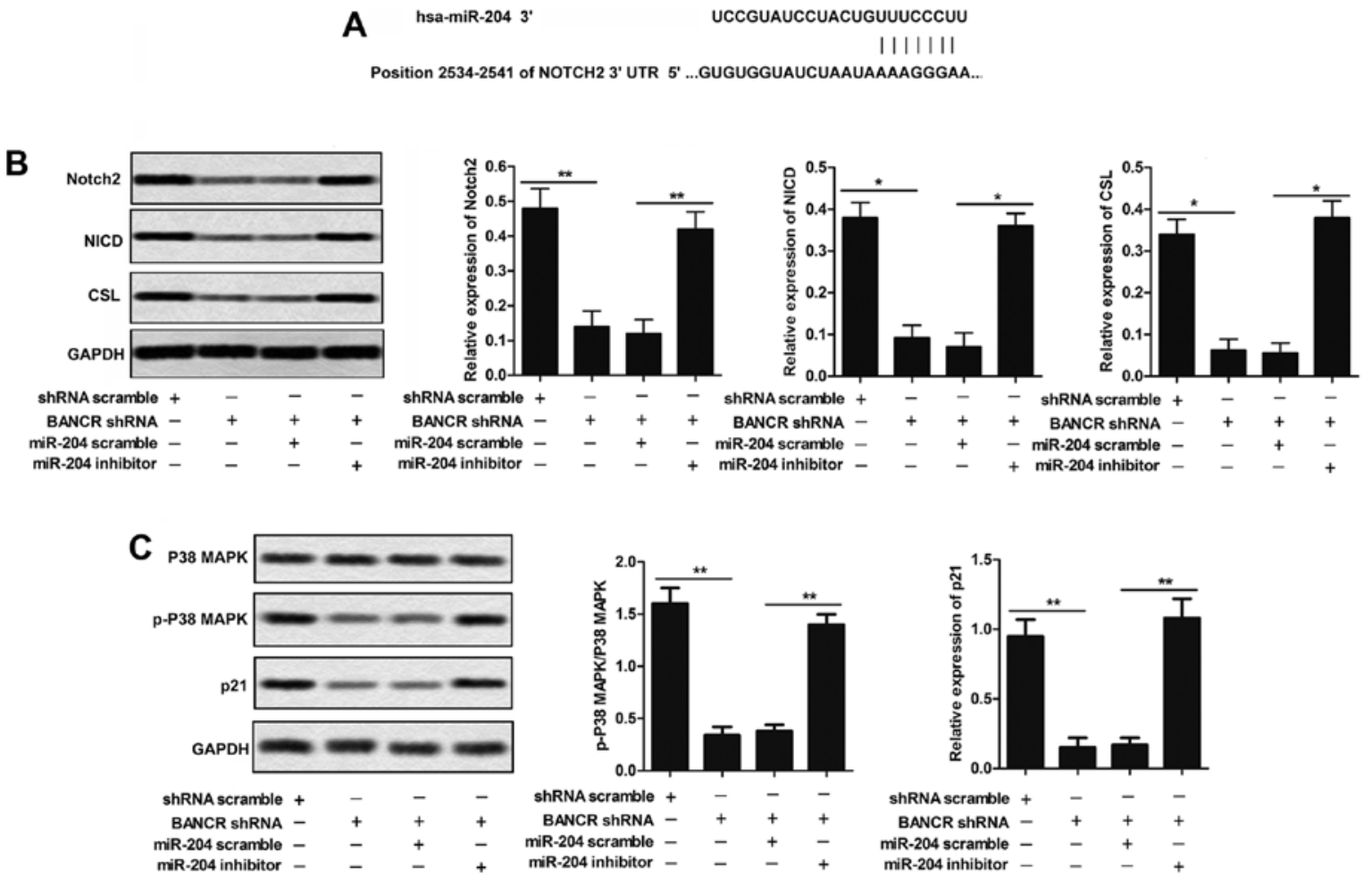

Figure 6. Regulation of Notch2 pathway by manipulation of BANCR and miR-204 in human melanoma cell line M14. (A) The targeting relationship between BANCR and Notch2 was predicted by bioinformatics. (B) The expression of Notch2, NICD and CSL were measured by western blotting in M14 cells transfected with BANCR shRNA or shRNA scramble in combination with miR-204 mock or miR-204 inhibitor. (C) The expression of P38MAPK, p-P38MAPK and p21 were also measured by western blotting in M14 cell. Data are presented as mean \pm SD of three independent experiments. ${ }^{*} \mathrm{P}<0.05$ and ${ }^{* *} \mathrm{P}<0.01$ indicates significant difference. 
A
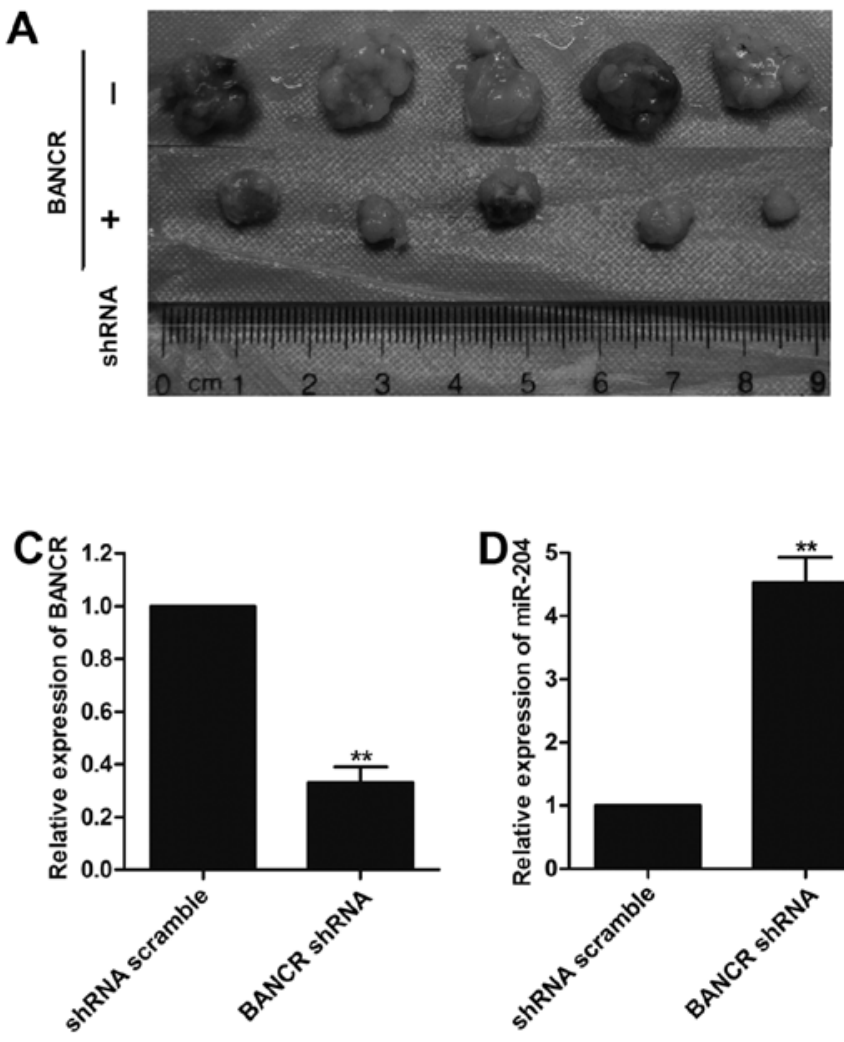

B

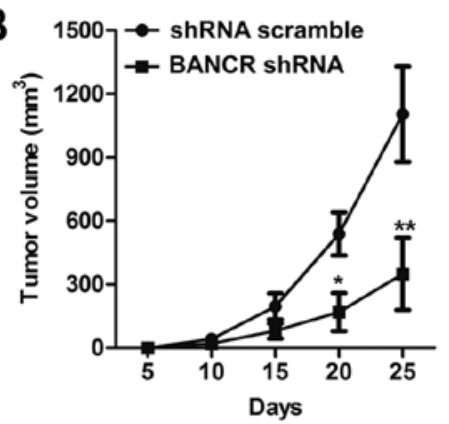

E
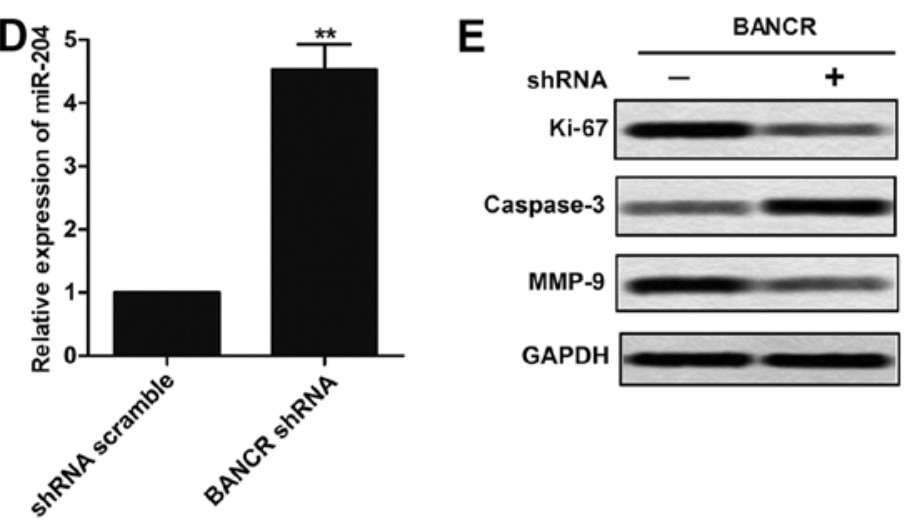
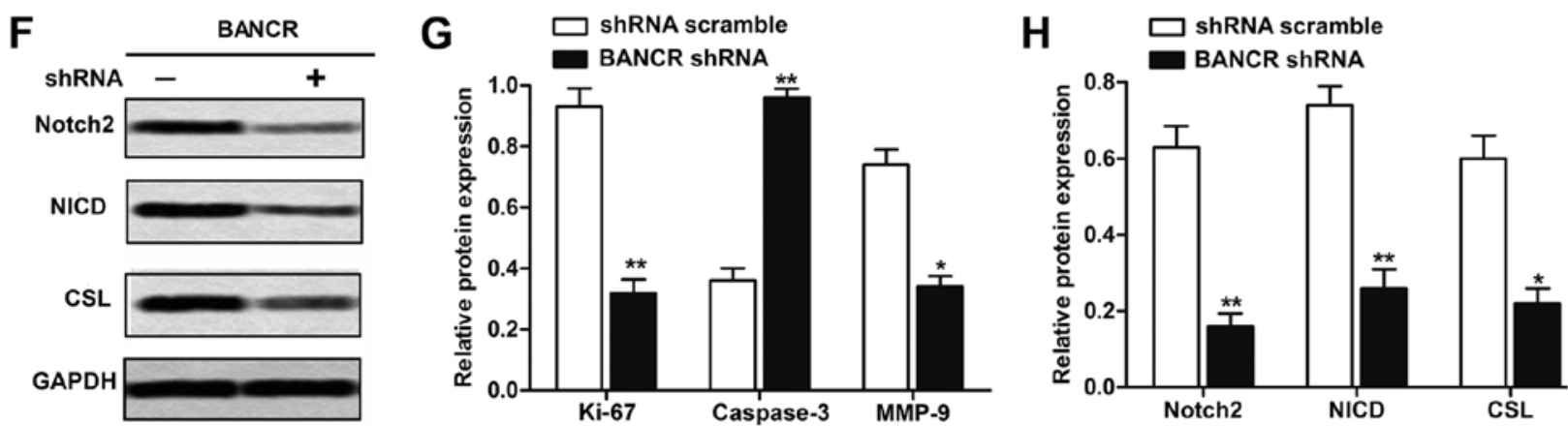

Figure 7. Effects of BANCR downregulation on tumorigenesis in a melanoma xenograft BALB/c mouse model. (A) Images of tumors after removal from the mice. M14 cells were transfected with BANCR shRNA or shRNA scramble and then injected subcutaneously into mice, respectively. (B) Tumor growth curve. Tumor volumes were measured every five days after injection of tumor cells. (C) Expression of BANCR in melanoma tissues. (D) Expression of miR-204 in melanoma tissues. (E and F) Effects of BANCR shRNA on the protein expression level of Ki-67, Cleaved caspase-3 and MMP-9 in melanoma tissues were determined by western blotting. (G and H) Effects of BANCR shRNA on the protein expression level of Notch2, NICD and CSL in melanoma tissues were determined by western blotting. Data are presented as mean $\pm \mathrm{SD}$ of three independent experiments. ${ }^{*} \mathrm{P}<0.05,{ }^{* * *} \mathrm{P}<0.01$ compared with the shRNA scramble group.

scramble group as demonstrated by western blotting. miR-204 inhibitor co-transfected with BANCR shRNA relatively upregulated Notch2, NICD and CSL compared with BANCR shRNA group in M14 cells ( $\mathrm{P}<0.05$, Fig. 6B). These results support a direct correlation of BANCR, miR-204, and Notch2 expression in the regulation of melanoma cell growth.

Downregulation of BANCR inhibits tumorigenesis of melanoma cells in vivo. To confirm whether the expression level of BANCR affects tumorigenesis in vivo, M14 cells transfected with BANCR shRNA or shRNA scramble were subcutaneously inoculated into nude mice. After injection, tumor growth in the BANCR shRNA group was obviously slower than that in the shRNA scramble group, especially after 20 days of observation ( $\mathrm{P}<0.05$, Fig. $7 \mathrm{~A}$ and $\mathrm{B})$. To confirm the mechanism through which BANCR exerts its oncogenic effects in melanoma, real-time qPCR was performed to analyze the mRNA expression of BANCR, miR-204 in melanoma tissues. As shown in Fig. 7C and D, BANCR shRNA obviously decreased the expression of BANCR and increased the expression of miR-204 compared with the shRNA scramble group $(\mathrm{P}<0.01)$. Furthermore, we also measured the expression of Ki-67, caspase-3 and MMP-9 in melanoma tissues. BANCR downregulation significantly increased the protein level of caspase-3, while reduced the Ki-67 and MMP-9 compared with shRNA scramble group $(\mathrm{P}<0.05$, Fig. $7 \mathrm{E}$ and $\mathrm{F})$. In addition, BANCR shRNA significantly decreased the protein levels of Notch2, NICD and CSL compared with control 
group, further indicating that Notch2 pathway indeed participates in the BANCR-mediated tumorigenesis of melanoma $(\mathrm{P}<0.05$, Fig. $7 \mathrm{G}$ and $\mathrm{H})$. These results demonstrate that BANCR/miR-204/Notch2 pathway plays a crucial role in melanoma cell growth in vivo.

\section{Discussion}

Genome-wide studies have identified thousands of lncRNAs lacking protein-coding capacity. Although lncRNAs only make up a small proportion of the entire genome, recent studies suggest that they facilitate normal growth and development and underpin disease when dysfunctional $(29,30)$. For example, IncRNA HOTAIR correlates with disease progression in bladder cancer (31). Particularly, elevated level of lncRNA is often associated with the progression of melanoma. For instance, the overexpressed lncRNA SLNCR1 promotes melanoma invasion through a conserved SRA1-like region (32). Upregulated lncRNA SPEY4-IT1 induces apoptosis and promotes invasion of melanoma (33). Although these studies are beginning to unravel the importance of lncRNAs in melanoma, their functions and mechanisms are largely unknown.

BANCR was found overexpressed in numerous cancer tissues and cell lines and may play an important role in the development of many malignancies. A report indicated that overexpressed BANCR is associated with poor prognosis for non-small cell lung cancer and promotes metastasis by affecting epithelial-mesenchymal transition (EMT) (15); BANCR promotes proliferation and invasion by regulating MMP2 and MMP1 via ERK/MAPK signaling pathway (16). Besides, BANCR promotes colorectal cancer migration by inducing epithelial-mesenchymal transition (14). Other reports have demonstrated that increased level of BANCR played a potential functional role in melanoma cell proliferation and migration through regulating MAPK pathway activation (17). Given the above reports, we applied BANCR in the context of melanoma in this study. In accordance with these reports, our study found that BANCR was highly expressed in melanoma and BANCR konckdown could significantly inhibit melanoma growth and migration, suggesting that BANCR functions as an oncogene in the melanoma progression.

MicroRNAs regulate a variety of normal physiologic processes, such as development, cell differentiation, and regulation of cell cycle and apoptosis, and are involved in pathogenesis of multiple malignancies, including melanoma (19,34). Reports suggest that miR-204 plays a dual regulatory role in cancer. Li et al, identified miR-204 an oncomiR through targeting prostate-derived Ets factor (PDEF) and inhibiting the PDEF tumor-suppressive function in PCa (35). miR-204 was also indicated to play a tumor suppressive function in PAC cells, but acts as an oncomiR in NEPC cells (36). However, accumulated evidence suggests miR-204 plays a prominent role in inhibiting the development of multiple types of cancer. For example, VHL-regulated miR-204 suppresses tumor growth through inhibition of LC3B-mediated autophagy in renal clear cell carcinoma (26). Besides, MALAT1 interacted with miR-204 to modulates human hilar cholangiocarcinoma proliferation, migration and invasion by targeting CXCR4 (37). These results suggest that an lncRNA-miRNA interaction might be important in the process of tumorigenesis. Consistent with the above studies, our results showed that an interaction between miR-204 and BANCR plays a role in the regulation of melanoma tumorigenesis.

The Notch pathway controls diverse processes, such as regulation of lymphoid development, differentiation and function (38) enhancing retinal pigment epithelial cell proliferation, while aberrant notch signaling has been identified in numerous tumor types, such as activation of the Notch pathway in head and neck cancer and in melanoma tissues and cell lines (39). Inhibition of Notch expression can suppress proliferation and invasion of melanoma (40). BANCR contributes to the progression of malignant melanoma by regulating MAPK pathway activation. Studies also showed that the activation of Notch pathway can be controlled by microRNAs in melanoma. For example, miR-146a promotes the initiation and progression of melanoma by activating Notch signaling (41). Given these reports together with our previous results, we speculated a BANCR/miR-204/ Notch axis in regulating melanoma. The results showed that BANCR knockdown induced suppressed growth, metastasis and inactivation of Notch pathway were counteracted by miR-204 inhibition. In addition, a melanoma xenograft animal model was carried out to evaluate the effects of BANCR on miR-204 and Notch2 expression in vivo, further indicating that miR-204 and Notch2 pathway indeed participate in the BANCR-mediated tumorigenesis of melanoma.

In conclusion, these data support the BANCR/miR-204/ Notch2 axis in melanoma tumor progression whereby BANCR promotes melanoma cell growth and migration through activating Notch2 pathway via targeting miR-204. This is the first time that BANCR, miR-204, and Notch2 have been linked in melanoma. A better understanding of the microRNA-lncRNA interaction and their regulation will provide new insight into mechanisms underlying various aspects of tumorigenesis including tumor growth and tumor-drug resistance, providing a new aspect for development of novel treatment strategies.

\section{References}

1. Siegel RL, Miller KD and Jemal A: Cancer statistics, 2016. CA Cancer J Clin 66: 7-30, 2016.

2. Linares MA, Zakaria A and Nizran P: Skin cancer. Prim Care 42: 645-659, 2015.

3. Singh S, Zafar A, Khan S and Naseem I: Towards therapeutic advances in melanoma management: An overview. Life Sci 174: 50-58, 2017.

4. Gray-Schopfer V, Wellbrock C and Marais R: Melanoma biology and new targeted therapy. Nature 445: 851-857, 2007.

5. Gros A, Parkhurst MR, Tran E, Pasetto A, Robbins PF, Ilyas S, Prickett TD, Gartner JJ, Crystal JS, Roberts IM, et al: Prospective identification of neoantigen-specific lymphocytes in the peripheral blood of melanoma patients. Nat Med 22: 433-438, 2016.

6. Slominski AT and Carlson JA: Melanoma resistance: A bright future for academicians and a challenge for patient advocates. Mayo Clin Proc 89: 429-433, 2014.

7. Shah DJ and Dronca RS: Latest advances in chemotherapeutic, targeted, and immune approaches in the treatment of metastatic melanoma. Mayo Clin Proc 89: 504-519, 2014.

8. Smith MA and Mattick JS: Structural and functional annotation of long noncoding RNAs. Methods Mol Biol 1526: 65-85, 2017.

9. Batista PJ and Chang HY: Long noncoding RNAs: Cellular address codes in development and disease. Cell 152: 1298-1307, 2013.

10. Martens-Uzunova ES, Böttcher R, Croce CM, Jenster G, Visakorpi T and Calin GA: Long noncoding RNA in prostate, bladder, and kidney cancer. Eur Urol 65: 1140-1151, 2014. 
11. Sun M, Xia R, Jin F, Xu T, Liu Z, De W and Liu X: Downregulated long noncoding RNA MEG3 is associated with poor prognosis and promotes cell proliferation in gastric cancer. Tumour Biol 35: 1065-1073, 2014

12. Sun M, Jin FY, Xia R, Kong R, Li JH, Xu TP, Liu YW, Zhang EB, Liu XH and De W: Decreased expression of long noncoding RNA GAS5 indicates a poor prognosis and promotes cell proliferation in gastric cancer. BMC Cancer 14: 319, 2014

13. Cai X, Liu Y, Yang W, Xia Y, Yang C, Yang S and Liu X: Long noncoding RNA MALAT1 as a potential therapeutic target in osteosarcoma. J Orthop Res 34: 932-941, 2016.

14. Guo Q, Zhao Y, Chen J, Hu J, Wang S, Zhang D and Sun Y: BRAF-activated long non-coding RNA contributes to colorectal cancer migration by inducing epithelial-mesenchymal transition. Oncol Lett 8: 869-875, 2014

15. Sun M, Liu XH, Wang KM, Nie FQ, Kong R, Yang JS, Xia R, Xu TP, Jin FY, Liu ZJ, et al: Downregulation of BRAF activated non-coding RNA is associated with poor prognosis for non-small cell lung cancer and promotes metastasis by affecting epithelialmesenchymal transition. Mol Cancer 13: 68, 2014.

16. Wang Y, Guo Q, Zhao Y, Chen J, Wang S, Hu J and Sun Y: BRAFactivated long non-coding RNA contributes to cell proliferation and activates autophagy in papillary thyroid carcinoma. Oncol Lett 8: 1947-1952, 2014

17. Li R, Zhang L, Jia L, Duan Y, Li Y, Bao L and Sha N: Long non-coding RNA BANCR promotes proliferation in malignant melanoma by regulating MAPK pathway activation. PLoS One 9: e100893, 2014.

18. Leucci E, Coe EA, Marine JC and Vance KW: The emerging role of long non-coding RNAs in cutaneous melanoma. Pigment Cell Melanoma Res 29: 619-626, 2016.

19. Philippidou D, Schmitt M, Moser D, Margue C, Nazarov PV Muller A, Vallar L, Nashan D, Behrmann I and Kreis S: Signatures of microRNAs and selected microRNA target genes in human melanoma. Cancer Res 70: 4163-4173, 2010.

20. Wang D, Wang D, Wang N, Long Z and Ren X: Long non-coding RNA BANCR promotes endometrial cancer cell proliferation and Invasion by regulating MMP2 and MMP1 via ERK/MAPK signaling pathway. Cell Physiol Biochem 40: 644-656, 2016.

21. Lv L, Jia JQ and Chen J: LncRNA CCAT1 upregulates proliferation and invasion in melanoma cells via suppressing miR-33a Oncol Res: Apr 12, 2017 (Epub ahead of print). doi: 10.3727/096 504017X14920318811749. 2017.

22. Sun Y, Cheng H, Wang G, Yu G, Zhang D, Wang Y, Fan W and Yang W: Deregulation of miR-183 promotes melanoma development via lncRNA MALAT1 regulation and ITGB1 signal activation. Oncotarget 8: 3509-3518, 2017.

23. Massi D, Tarantini F, Franchi A, Paglierani M, Di Serio C, Pellerito S, Leoncini G, Cirino G, Geppetti P and Santucci M: Evidence for differential expression of Notch receptors and their ligands in melanocytic nevi and cutaneous malignant melanoma. Modern Pathol 19: 246-254, 2006.

24. Suliman MA, Zhang Z, Na H, Ribeiro AL, Zhang Y, Niang B, Hamid AS, Zhang H, Xu L and Zuo Y: Niclosamide inhibits colon cancer progression through downregulation of the Notch pathway and upregulation of the tumor suppressor miR-200 family. Int J Mol Med 38: 776-784, 2016.

25. Chegeni S, Khaki Z, Shirani D, Vajhi A, Taheri M, Tamrchi Y and Rostami A: Investigation of MMP-2 and MMP-9 activities in canine sera with dilated cardiomyopathy. Iran J Vet Res 16 $182-187,2015$.
26. Mikhaylova O, Stratton Y, Hall D, Kellner E, Ehmer B, Drew AF, Gallo CA, Plas DR, Biesiada J, Meller J, et al: VHL-regulated miR-204 suppresses tumor growth through inhibition of LC3B-mediated autophagy in renal clear cell carcinoma. Cancer Cell 21: 532-546, 2012.

27. Bao W, Wang HH, Tian FJ, He XY, Qiu MT, Wang JY, Zhang HJ, Wang LH and Wan XP: A TrkB-STAT3-miR-204-5p regulatory circuitry controls proliferation and invasion of endometrial carcinoma cells. Mol Cancer 12: 155, 2013

28. Yin Y, Zhang B, Wang W, Fei B, Quan C, Zhang J, Song M, Bian Z, Wang Q, Ni S, et al: miR-204-5p inhibits proliferation and invasion and enhances chemotherapeutic sensitivity of colorectal cancer cells by downregulating RAB22A. Clin Cancer Res 20: 6187-6199, 2014.

29. Fatica A and Bozzoni I: Long non-coding RNAs: New players in cell differentiation and development. Nat Rev Genet 15: 7-21, 2014.

30. Shi X, Sun M, Liu H, Yao Y and Song Y: Long non-coding RNAs: A new frontier in the study of human diseases. Cancer Lett 339: 159-166, 2013.

31. Berrondo C, Flax J, Kucherov V, Siebert A, Osinski T, Rosenberg A, Fucile C, Richheimer S and Beckham CJ: Expression of the long non-coding RNA HOTAIR correlates with disease progression in bladder cancer and is contained in bladder cancer patient urinary exosomes. PLoS One 11: e0147236, 2016.

32. Schmidt K, Joyce CE, Buquicchio F, Brown A, Ritz J, Distel RJ, Yoon $\mathrm{CH}$ and Novina CD: The lncRNA SLNCR1 mediates melanoma invasion through a conserved SRA1-like region. Cell Rep 15: 2025-2037, 2016

33. Khaitan D, Dinger ME, Mazar J, Crawford J, Smith MA, Mattick JS and Perera RJ: The melanoma-upregulated long noncoding RNA SPRY4-IT1 modulates apoptosis and invasion. Cancer Res 71: 3852-3862, 2011.

34. Garzon R, Calin GA and Croce CM: MicroRNAs in cancer Annu Rev Med 60: 167-179, 2009.

35. Li T, Pan H and Li R: The dual regulatory role of miR-204 in cancer. Tumour Biol 37: 11667-11677, 2016.

36. Ding M, Lin B, Li T, Liu Y, Li Y, Zhou X, Miao M, Gu J, Pan H, Yang $\mathrm{F}$, et al: A dual yet opposite growth-regulating function of miR-204 and its target XRN1 in prostate adenocarcinoma cells and neuroendocrine-like prostate cancer cells. Oncotarget 6: 7686-7700, 2015

37. Tan X, Huang Z and Li X: Long Non-coding RNA MALAT1 interacts with miR-204 to modulate human hilar cholangiocarcinoma proliferation, migration, and invasion by targeting CXCR4. J Cell Biochem 118: 3643-3653, 2017.

38. Maillard I, Fang T and Pear WS: Regulation of lymphoid development, differentiation, and function by the Notch pathway. Annu Rev Immunol 23: 945-974, 2005.

39. Schouwey K, Aydin IT, Radtke F and Beermann F: RBP-JK-dependent Notch signaling enhances retinal pigment epithelial cell proliferation in transgenic mice. Oncogene 30: 313-322, 2011.

40. Asnaghi L, Ebrahimi KB, Schreck KC, Bar EE, Coonfield ML, Bell WR, Handa J, Merbs SL, Harbour JW and Eberhart CG: Notch signaling promotes growth and invasion in uveal melanoma. Clin Cancer Res 18: 654-665, 2012.

41. Forloni M, Dogra SK, Dong Y, Conte D Jr, Ou J, Zhu LJ, Deng A, Mahalingam M, Green MR and Wajapeyee N: miR-146a promotes the initiation and progression of melanoma by activating Notch signaling. eLife 3: e01460, 2014. 